\title{
Seeing as though ${ }^{1}$
}

\author{
JOHN R. TAYLOR \\ University of Otago \\ and \\ KAM-YIU S. PANG \\ University of Macau
}

(Received 4 April 2007; revised 13 September 2007)

\begin{abstract}
In this article we address a hitherto unstudied causal conjunction in English, seeing as though. Occurring predominantly in informal registers, the conjunction is typically used to introduce information which the speaker takes to be self-evidently true and on whose basis some further comment, or query, is made. Drawing on data derived from internet searches we draw up a semantic profile of the expression in comparison and contrast with other reason connectives, namely, seeing (that) and since. The data suggest that seeing as though is associated with highly subjective construals of the reason relation. We also address the internal structure of the expression. The use of seeing in a reason conjunction is traced to a common conceptual metaphor, whereby KNOWING IS SEEING. More puzzling is the occurrence of as though. While rejecting the possibility of a compositional analysis of the expression, we note that as though is only one of a number of items which can occur with causal seeing. These items have to do with the appearance of things and are in fact able to occur as complementizers after predicates of seeming and appearing. To this extent, as though is consistent with the subjectivity associated with the complex conjunction. In the course of our investigation, we also document the extraordinary proliferation of reason connectives that involve lexical items such as seeing, as, though, and several others, and suggest that this exuberance of new forms may not be unrelated to the subjectivity inherent in the construal of causal relations.
\end{abstract}

\section{Introduction}

The impetus for this article came from an email which a student sent to the first author. The student raised the question of who should supervise her research project. The project was on a topic in the linguistics of German and the student suggested that Dr X might be an appropriate choice, 'seeing as though she is a native speaker of German'. There might be a problem with this arrangement, the student continued, 'seeing as though' Dr X was soon going to be absent on study leave. So perhaps Dr Y would be a better choice, 'seeing as though' Dr Y did not appear to have too many other supervisory commitments.

In the course of this short email there were three occurrences of seeing as though. The expression served as a subordinating conjunction, with roughly the same value

\footnotetext{
${ }^{1}$ Portions of this paper were presented at the Facultés universitaires Saint-Louis in Brussels and at ICLCE2 in Toulouse. We are grateful to Elizabeth Traugott and to two anonymous reviewers for insightful comments on earlier versions. The usual disclaimers apply.
} 
as more common alternatives such as since and seeing that. More specifically, the expression appeared to be being used to introduce information which was taken as given, evident to both writer and reader, and on whose basis some further assertion or query could be made.

The expression was not in the productive repertoire of either of the authors. What particularly attracted our attention, however, was its internal makeup and the fact that this did not seem to match its semantics. It is not at all remarkable that a subordinated reason clause should be introduced by seeing (a matter we return to later). But what is as though doing there? Elsewhere in the language, as though (as in It seemed as though I had been there before) introduces an irrealis, nonfactual clause. In the uses cited above, however, seeing as though introduces clauses whose content is factual and taken for granted. Neither do the examples carry any hint of concession, the typical semantic value of though.

We decided to look into the matter further. This article is a report on our investigations.

Section 2 addresses the incidence and currency of the expression, while section 3 documents several other reason conjunctions which involve the word seeing. We then turn to the expression's semantics. We consider, first, some aspects of reason clauses in general, with particular reference to their subjectivity, or speaker-centredness (section 4). In section 5 we draw up a semantic profile of the expression, based on the analysis of a small database of 50 examples of seeing as though and the contexts in which the expression occurs. In order to better evaluate our findings, we compare the profile of seeing as though with that of two other reason connectives, seeing that and since. Our general finding is that seeing as though is associated with highly subjective contexts of use. Turning to the internal structure of the expression, we address, in section 6, the development of seeing (that) into a reason connective, and discuss, in section 7, the incidence of as though in the complex conjunction. In the course of this discussion we document the fact that seeing as though is only one of a large and possibly growing cluster of lexically related expressions, all of which function as (admittedly, sub-standard) conjunctions of reason. Section 8 sums up our investigation.

\section{Incidence of the expression}

Intrigued by the expression, we first checked it out in standard reference works. There is no mention of it in Huddleston \& Pullum et al. (2002) or in Biber, Johannsson, Leech, Conrad \& Finegan (1999), or in any other reference grammar we consulted. It is not recorded in the American Heritage Dictionary or in Webster's, nor did the full text search of the $O E D$ return any instances. Neither were any occurrences found in the 56-million-word 'sampler' corpus of the Bank of English. ${ }^{2}$ Searches of the Modern

\footnotetext{
2 Accessed at http://www.collins.co.uk/Corpus/CorpusSearch.aspx.
} 
English Collection of the University of Virginia Corpus (comprising texts from 1500 onwards) ${ }^{3}$ and of the Literature Network ${ }^{4}$ also drew a blank.

Its absence from these resources could indicate that the expression is a rather recent innovation. Another possibility is that the expression - whether a recent innovation or not - is restricted to informal registers. As a matter of fact, two examples were found in the British National Corpus (BNC). As will be apparent from their syntax, the examples occurred in the unscripted spoken sections of the corpus.

(1) (a) And anot in a careers officer's view the other day, that seeing as though they'd worked there twenty years ago, they wanted to go back and see how it had changed.

(b) No seeing as though they've been produced I've said I all in favour of the jury seeing anything that's referred to and then there, there's no mystery about it then.

The BNC comprises about 100 million words of text and is heavily biased towards the written language ${ }^{5}$ consequently, expressions restricted to spoken domains are not likely to be well represented. Moreover, since the BNC is a snapshot of (British) English in the late twentieth century, it is not a good source for more recent innovations in the language. We therefore proceeded to check out the expression on the World Wide Web, using the Google search engine. Since much of what we have to say about seeing as though (and other reason connectives) in this article will be based on results of Google searches, we first say a few words on the use of the World Wide Web as a source of linguistic data.

It has been estimated that in 2002 Google was able to access a database of over 3,000 million indexed web pages, more than any of its rivals (Notess 2002). Nowadays, no doubt, we can expect the database to be many times larger. The BNC at a mere 100 million words is minuscule in comparison. Prima facie, the Web should be an invaluable source of linguistic data, especially for expressions which are sparsely represented in conventional corpora of limited size.

Several objections can be raised against accessing the Web for linguistic and lexical research. Unlike with established linguistic corpora, the composition of the Web is not controlled for factors such as genre, register, or the sociocultural background of the authors of the texts. On top of that, the data are inevitably sensitive to the time at which a search is performed, in that topical issues and current events are liable to skew the search results. On the other hand, the vast size of the Web will tend to smooth out idiosyncrasies and irregularities in usage (including those attributable to non-native authors). Moreover, the very currency of the content affords us a vista of the present state of the language, one as up-to-date and as 'representative' (Kilgarriff \& Grefenstette 2003) as we could imagine. A second objection concerns the status of the reported frequencies. It is impossible to determine the amount of text which is

\footnotetext{
3 Accessed at http://etext.lib.virginia.edu/etcbin/ot2www-pubeng?specfile=/texts/english/modeng/publicsearch/ modengpub.o2w.

4 Accessed at http://www.online-literature.com/.

5 Information obtained from the BNC website: http://www.natcorp.ox.ac.uk/docs/userManual/design.xml.
} 
being accessed in a search. Search engine results, therefore, can give no indication of the absolute frequency of an item per so many million words. At most, we can gain a very rough idea of the relative frequency of search items. The matter is, however, complicated by the frequency reporting mechanism itself. Webmasters are familiar with various tricks for increasing the hit rate for their documents; indeed, it is a common observation with many searches that some documents are reported more than once, and some have a habit of always appearing on top. These distortions are most likely to be encountered on searches for topical content phrases, which are likely to be the subject of links to other web pages, rather than with nondescript discourse connectives. Even searches for nontopical phrases, though, will probably be distorted to some unknown degree. It is of comfort, then, to learn that in terms of relative frequency, the Web may actually outperform conventional corpora. Keller, Lapata \& Ourioupina (2002) found that Googled frequencies for three kinds of bigrams (adjective-noun, verb-object, and noun-noun) correlated better with informants' acceptability judgements than data obtained from the BNC.

Our first Google search (June 2004) for seeing as though returned 10,000 hits. One year later (May 2005) we obtained 30,000 hits. Subsequent searches (May and August 2006) returned as many as 218,000 and 255,000 hits, respectively. ${ }^{6}$ It would be unwise to draw any conclusions from these numbers about the increased frequency of the expression. (The figures could simply reflect the increased size of the accessed database, or modifications to the search algorithm.) The hit rate is, however, suggestive of the currency of the expression (it was not unusual to find two or more examples within a single web-page), at least in some registers, notwithstanding its absence from all the reference works that we consulted.

Here are three Googled examples. These confirm our initial characterization of seeing as though as a complex conjunction which introduces a clause whose content is evoked by the speaker in order to justify, or explain, the content of the main clause. The association of the expression with informal registers (blogs, chatroom discussions, etc.), as well as their occurrence in both North American (2a) and British (2b) texts, will also be evident.

(2) (a) Prior to working at an elementary school, I had a very one-dimensional view of how schools actually ran, seeing as though my last encounter with a peewee educational fortress was many years ago.

(b) the promotional advert in question told me I would get $£ 10.00$ off my first purchase, as long as it was above $£ 20.00$, so I took an investigative look and seeing as though I needed some CDR's, I thought I might actually purchase something off the site, so I clicked on the link.

(c) Creating a human-alien hybrid.

Seeing as though most animals aren't even able to breed with each other, it is extremely unlikely for an alien to achieve this.

\footnotetext{
${ }^{6}$ A later search (March 2007), however, returned 'only' 135,000 hits. Presumably, the lower hit rate reflects
} changes to Google's search algorithm, not the reduced incidence of the expression. 


\section{A cluster of connectives}

There are several connectives in English which have a similar semantic value to seeing as though. These include, most obviously, since, but also a number of locutions based on seeing. Perhaps the best entrenched of these is seeing that. The expression is well represented in the BNC and is listed as a conjunction in Huddleston \& Pullum et al. (2002: 731). The earliest uses recorded in the $O E D$ date from the beginning of the sixteenth century:

(3) (a) 1503. Paston Lett. III. 401. I wol..exhorte you to take it as..paciently as ye can, seeyng that we al be mortal and borne to dey.

(b) 1526. TINDALE John ii. 18. What token shewest thou vnto vs, seynge that thou dost these thinges?

Also dating from the sixteenth century - though lagging a little behind seeing that - is the use of 'bare' seeing (without the complementizer that) as a conjunction:

(4) (a) 1537. CRANMER in Ellis Orig. Lett. Ser. I. II. 77. As towching the house of the Charterhouse I pray ... that it may be turned into a better use (seing it is in the face of the world).

(b) 1711. PUCKLE Club (1817) 35. Seeing Great Britain affords so many lawyers, ... he is doubly a fool that ... applies himself to a scab.

Of interest to our topic are attestations of another reason conjunction based on seeing, namely seeing as. This appears to have been current by the nineteenth century, as the following $O E D$ example testifies:

(5) 1833. DICKENS Let. 18 Mar. (1965) I. 17. Seeing as I cannot fail to do that I have engaged in a pursuit.

A search of the University of Virginia Corpus turned up several nineteenth-century examples and one from the eighteenth century:

(6) (a) 1749. Fielding, Henry: The History of Tom Jones. but, on the contrary, han't I offered to bind down my land in such a manner, that I could not marry if I would, seeing as narro' woman upon earth would ha me.

(b) 1883. Stevenson, Robert Louis: Treasure Island. and I shouldn't wish for to see the party weakened, let alone yourself, seeing as I know what I owes you.

About this time, seeing as how also makes its appearance. The earliest example in the Virginia Corpus is (7a). A somewhat later example is recorded in the OED (7d).

(7) (a) 1794. Rowson, Susanna Haswell: Charlotte Temple, A Tale of Truth. but let me tell you, my fine spoken Ma'am, I must have my money; so seeing as how you can't pay it, why you must troop, and leave all your fine gimcracks and fal der ralls behind you.

(b) 1847. Prest, Thomas Preskett: Varney the Vampire; or, The Feast of Blood. 'Why, as for the roses,' said Jack, 'I'm blowed if I can tell, and seeing as how she don't look at me much, I doesn't know nothing about her; I can tell you something, though, about the old admiral that will make you open your eyes.' 
(c) 1861. Mayhew, Henry: London Labour and the London Poor. 'We did intend petitioning the Prince on the subject, but I don't suppose it would be any go, seeing as how the slang coves' (the showmen), 'have done so, and been refused.'

(d) 1895. Dialect Notes I. 399. Seein' as how it's you, I'll do so-and-so.

A number of commentators have remarked on the stylistic value of these options. The American Heritage Dictionary of Idioms (Ammer 1997) avers that seeing as and seeing as how are colloquial variants of seeing that, 'recorded from the second half of the 1900s, although they probably have been in much longer use orally'. The Columbia Guide to Standard American English (Wilson 1993) ${ }^{7}$ also notes their nonstandard status:

The participial Seeing [that] she wasn't ready, he sat down is Standard. Seeing as and seeing as how are conjunctions meaning 'because' and are limited to the lower levels at best; some conservatives consider both locutions - especially seeing as how - countrified and unacceptable at any level.

The Guide also comments on as how:

a Nonstandard dialectal (especially Midland and Southern) locution meaning 'that', especially when combined with the verbs say and allow or the present participles seeing and being: She allowed [said] as how she might be interested. Seeing [being] as how we were ready, we went off without waiting for her.

Presumptions concerning the 'dialectal' and 'countrified' character of seeing as how are supported by the citations in (7). However, more recent attestations indicate that the expression has to some extent lost these connotations, though still retaining its colloquial character. The following is from the $O E D$ :

(8) 1974. S. GULLIVER Vulcan Bulletins 29. Seeing as how you're always short of £sd, I thought you could maybe earn a bit.

In light of the above, it is plausible to take seeing as though as yet another colloquial variant of already existing locutions, one which has not yet found its way into reference works and which is not yet subject to prescriptivist condemnation. (We shall see in due course that several more variants are making their appearance in the language.) Such a development, however, is still in need of explanation. Why have speakers of English, over the centuries, felt the need to create variants of already existing expressions, a need which is apparently still being felt today? After all, seeing that, and even since (not to mention because), could serve as perfectly adequate markers of the causal relation. A further question concerns the items which speakers recruit in the creation of these new variants. Seeing that - as we shall discuss in section 6 - is reasonably transparent. But why should speakers choose to create variants with as and how, and, more recently, as though? These are the questions which we hope to address in this article.

Our first task is to examine more closely the semantics of reason conjunctions. Then, in section 5, we attempt to draw up a semantic profile of seeing as though in comparison

\footnotetext{
${ }^{7}$ Accessed at http://www.bartleby.com/68/53/5353.html.
} 
and contrast with other conjunctions of reason. To anticipate our findings: it turns out that seeing as though signals a highly subjective and speaker-centred construal of the causal relation.

\section{Reason, cause, and subjectivity}

As a conjunction of reason, seeing as though (along with since, seeing that, seeing as, and many more) falls under the more general category of causal connective. ${ }^{8}$ In this section we review some general properties of causal relations, focusing on aspects of subjectivity and information structure.

\subsection{Subjectivity}

Lyons $(1981,1982,1995)$ draws attention to the inadequacies of objectivist theories of semantics, where the speaker is little more than a neutral reporter of propositions derived from observation of the external world. These approaches ignore the role of subjectivity in language, that is, 'the way in which natural languages, in their structure and normal manner of operation, provide for the locutionary agent's expression of himself and his own attitudes and beliefs' (Lyons 1982: 102; see also Finegan 1995; Scheibman 2002; and Traugott 1995 for comparable approaches). The speaker's self is not only the location of his beliefs, emotions, and attitudes, it is also 'the product of the social and interpersonal roles that he has played in the past', as well as 'the role that he is playing in the context of utterance' (Lyons 1981: 240).

Subjectivity, in the sense of the speaker's self expression, has been the focus of considerable interest in recent years (Athanasiadou, Canakis \& Cornillie 2006; Stein \& Wright 1995; Traugott \& Dasher 2002). As these references indicate, subjectivity has many ramifications for the study of linguistic and semantic structure. Here, we wish to draw attention to three of its manifestations which will prove to be important for our study of causal connectives.

A first, and obvious, manifestation of subjectivity concerns the speaker's expression of her attitude towards the things and events she is talking about, as revealed by sentence adverbials such as regrettably, fortunately, and the like. Subjectivity also concerns the speaker's epistemic stance, that is, her degree of commitment to the truth of the expressed proposition (Traugott, 1989: 35; see also Traugott, 1995). On the basis of evidence available to her, in association with background assumptions concerning, for example, the likely course of events, a speaker may infer that a proposition may be true, can't be true, or must be true. Of special status in this connection are expressions in which the speaker explicitly talks about herself - her physical and emotional state, her past experiences, her decisions, intentions, wishes, and hopes, as well as her relations (present and past) with her interlocutors and with others. In contrast with statements

\footnotetext{
${ }^{8}$ In Halliday \& Hasan's (1976: 243) taxonomy of conjunctive relations, Reason is classified as a sub-category of causal relation, along with Result and Purpose.
} 
concerning third parties and 'objective' states of affairs in general, a speaker's talk about herself comes with an epistemic guarantee, as it were, in the sense that the speaker is (or can consider herself to be) the ultimate authority on how she feels, what she wants, and what she has experienced. But even a plain statement of fact is imbued with a degree of subjectivity, to the extent that the speaker opts to present her particular construal of the situation (Langacker 1987: 128ff.). Moreover, every statement of fact is made against the speaker's presumption that the hearer is ignorant of this fact and would be interested to be informed about it. In this connection, we might more appropriately speak of intersubjectivity (Traugott in press; Traugott \& Dasher 2002: 20; Verhagen 2005).

\subsection{Cause and reason}

Some semanticists refer to 'cause' as a semantic primitive, a predicate which enters into the semantic structure of certain lexical items and larger constructions (Goldberg 1995; McCawley, 1976). Others have emphasized the multifaceted and heterogeneous nature of causation, denying that it is a simple and undifferentiated, unanalysable concept (Lakoff \& Johnson 1980: ch. 14; Talmy 1988). In the following, we seek to emphasize the inherently subjective and context-dependent nature of causal relations.

Consider a seemingly straightforward example of what looks like an objectively construed relation.

(9) The temperature has risen above zero. \{Therefore, so, because of this, for this reason, etc. $\}$ the snow is melting.

Here we are presented with two situations, S1 and S2, whereby the occurrence of S1 caused S2 to come about. The relation may be explicated in terms of a counterfactual conditional: if S1 had not happened, S2 would not have happened. We may be confident of the validity of this kind of reasoning since it rests on natural laws and the necessity of certain outcomes, given a prior situation (Lewis 1973).

Example (9) exhibits what Halliday \& Hasan (1976: 242) refer to as an external relation, that is, the relation holds in the outside world, independent of a human observer. Nevertheless, a certain degree of subjectivity inheres in our recognition even of the causal relation in (9). Although the relation is external and based on laws of nature, there is still involvement by the speaking subject. As Humean skeptics remind us, the truth of a natural law, and the necessity of cause-result relations, can never be decisively determined; our understanding of the workings of nature is contingent on previous observations and experience. Secondly, the validity of the relation is dependent on background assumptions, which, more often than not, are never explicitly stated (Meyer 2000). For example, both (9) and its counterfactual rewording presuppose normal atmospheric pressure. These presupposed conditions also play their part as causal factors in the occurrence of S2. A speaker selectively focuses on just one of a large (and possibly indeterminate) number of such factors. Thirdly, a speaker makes a choice regarding which links in the causal chain she wishes to highlight. There are events at the molecular level which intervene between the rise in the temperature and 
the melting of the snow, which are telescoped in (9). Alternatively, the speaker may zoom out, as it were, and declare that the melting of the snow was caused by the onset of spring, or by the warm westerly wind.

When we turn our attention to a wider range of examples we observe an increase in the subjective component. (In such cases we might be more inclined to describe the relation as one of reason, rather than cause.) There are two main dimensions of increasing subjectivity. Consider, first, the following examples.

(10) (a) The snow is melting because the temperature is rising.

(b) The temperature is rising, because the snow is melting,

(c) Do you want a lift, because I'm leaving now.

(10b) appears to reverse the causal relation in (10a), and indeed it makes no sense to assert that the melting of the snow causes the temperature to rise. (For a discussion of 'backward' causals, see Pit 2006.) To be sure, (10b) presupposes the external relation. The speaker's knowledge that such a relation in general holds entitles her to draw an inference about the causing event, S1, given only her observation of the consequence, $\mathrm{S} 2$. The relation in (10b) is therefore epistemic ('internal', in Halliday \& Hasan's terms), having to do with the reason, not why $\mathrm{S} 1$ is true, but why the speaker believes it is legitimate to believe S1, and hence to assert S1. Turning to (10c), the relation is no longer between two propositions. Rather, the second clause is presented as a factor which legitimizes the speaker's making the speech act of an offer.

The contrasts in (10) illustrate Sweetser's (1990: 76-9) distinction between the content, epistemic, and speech-act domains of causal relations. There is, however, another dimension to the subjectivity of causal relations. Compare the examples in (11).

(11) (a) The snow is melting because the temperature is rising.

(b) She left the party because it was getting late.

Both examples have to do with events in the external world. But whereas the relation in (11a) concerns the workings of a natural law, in (11b) the relation is mediated by the decision of a conscious agent. On what is perhaps the most natural interpretation of (11b), the woman became aware that it was getting late (S1) and decided, on that basis, that it was necessary, or appropriate, that she should leave (S2). The subjectivity of the relation is therefore not primarily located with the speaker but with the decision-making agent. Even so, we can identify increasing degrees of speaker-centred subjectivity. For example, the speaker may simply be reporting the causal relation entertained by the protagonist: 'She told me why she left, namely, because it was getting late.' On another, and more intrinsically subjective interpretation, the speaker empathizes with the protagonist, reconstructing her mental processes. There is a third possibility, which imputes no decision-making to the protagonist. ${ }^{9}$ Suppose the woman in question habitually leaves parties early. For the speaker, the relation between S1 and S2 would

\footnotetext{
9 This interpretation is likely to be associated with 'comma intonation', discussed in section 4.3.
} 
be part of the normal course of events. In this case it would be the speaker, not the protagonist, who establishes the relation between the events.

These matters have been discussed by Pander Maat \& Sanders $(2000,2001)$ in terms of the conceptual distance between the speaker and a 'Subject-of-Consciousness' (SoC) ${ }^{10}$ Concerning (11b), on the first of the interpretations discussed above, the $\mathrm{SoC}$ is the woman, who decided to leave when she observed that it was getting late. The conceptual distance between speaker and $\mathrm{SoC}$ is maximal. Conceptual distance decreases (and subjectivity increases) in case a speaker reports her own volitional actions (12a). Conceptual distance is minimized if the speaker refers to her own current circumstances and current decision-making (12b).

(12) (a) I left the party because it was getting late.

(b) I'm leaving now because it's getting late.

\subsection{Information structure}

Dancygier \& Sweetser (2005) draw a broad distinction between two kinds of causal conjunctions. We can refer to these as because-type conjunctions and since-type conjunctions. A 'test' for the two types has to do with whether the causal relation is compatible with various focusing strategies. Because-type conjunctions permit focusing, negation, and contrast; since-type conjunctions do not. Example (11b) permits the variations in (13). Analogous sentences with since are not possible (14).

(13) (a) It was because it was getting late that she left the party.

(b) She didn't leave the party because it was getting late but because she was feeling sick.

(14) (a) *It was since it was getting late that she left the party.

(b) *She didn't leave the party since it was getting late but since she was feeling sick.

Conjunctions which pattern like since include as, for, and, of course, seeing (that) and seeing as though. Because-type connectives include due to (the fact that), for the reason that, and in view of (the fact that).

As a matter of fact, the term 'because-type conjunction' is not ideal, in that because can sometimes pattern with the since-type conjunctions. Consider the following contrast (cf. Dancygier \& Sweetser 2005: 180-3). In (15a) - written without the comma and spoken as a single intonation unit - the speaker gives the reason why the person left. In (15b) - written with a comma and spoken as two intonation units - the speaker asserts that the person left, and then states the reason why this event happened, or why she feels entitled to state that it happened.

(15) (a) She left the party because it was getting late.

(b) She left the party, because it was getting late.

${ }^{10}$ Pander Maat \& Sanders $(2000,2001)$ investigate the relevance of this dimension to the differentiation of causal connectives (dus, daarom, doordat) in Dutch. See also Pit (2006). 
The contrast becomes clearer if the sentences are embedded under an epistemic verb:

(16) (a) I believe she left the party because it was getting late.

(b) I believe she left the party, because it was getting late.

In (16a) the reason is part of the speaker's belief; in (16b) the fact that it was getting late is adduced in support of the speaker's belief. The commaless version (16a) exemplifies a because-type relation, (16b) exemplifies a since-type relation. ${ }^{11}$

De Smet \& Verstraete (2006: 383) propose for because-type causals the semantic structure (I assert [ $X$ is caused by $Y]$ ). The formula captures the status of the causal clause as part of a complex proposition. For since-type constructions they suggest the structure (I assert X, I say it is caused by Y). The formula highlights the illocutionary independence of the causal clause. The incorporation of the $I$ say component also recognizes the inherent subjectivity of a since-type conjunction.

De Smet \& Verstraete's formulas have the causal clause in second position. Their explications should not, of course, be taken as mapping directly onto the linear sequence of clauses. Indeed, for many of the connectives, both initial and final position of the causal clause are fully acceptable (a fact which may be verified on the examples cited in this article). Nevertheless, differences in the preferred order for the two types might be expected, due to the different information structures associated with them.

In a because-type construction, as in (15a), the main clause is likely to contain presupposed, or given information, the speaker's point in making the utterance being to state the reason why the state of affairs came about (Dancygier \& Sweetser 2000: 135). On the presumption that given information is likely to be presented first (Prince 1980), we would expect because-type clauses to occur in sentence-final position. In a since-type construction, on the other hand, the reason clause is typically taken as presupposed. The speaker first lays out presupposed information and then builds on this with the assertion, query, or whatever, that she is intent on making (Verhagen 2005: 170). The reason clause might thus be expected to occur in initial position. These ordering preferences have been confirmed in several studies (Altenberg 1984; Diessel 2001, 2005; Ford, 1993). Deviations from the preferred orders can, of course, be expected. A since-clause might be postposed, almost as an afterthought, in case the speaker seeks to justify, post hoc, the content of the main clause.

We have said that the information introduced by a since-type conjunction is likely to be presupposed, as when the speaker takes up material already introduced into the discourse, summarizing it or alluding to it. Alternatively, the speaker refers to generally accepted facts, which might reasonably be taken to be common knowledge. We should also bear in mind the possibility that the speaker insinuates, for rhetorical effect, that the

11 Keller (1995) draws a similar distinction with regard to German weil. With verb-final syntax, a weil-clause functions as a because-type conjunction: Er ist nach Hause gegangen, weil er Kopfweh hatte 'He went home because he had a headache'. 'Epistemic weil', however, has main clause (verb-second) syntax, and functions as a since-type conjunction: Er ist nach Hause gegangen, weil er hatte Kopfweh. 
content of the reason clause is presupposed and therefore beyond dispute. Especially this last possibility can make it difficult in practice to assess whether the information in a clause really is presupposed or is newly asserted. As a result, the claim that sincetype conjunctions introduce presupposed information might be difficult to confirm empirically.

There are, however, cases where this interpretative uncertainty does not arise (cf. Dancygier \& Sweetser 2000: 129-30). One case is where the information in the sinceclause pertains to the hearer, or to an experience previously shared by hearer and speaker. Such information is, presumably, accessible to the hearer; the speaker is, at most, simply reminding him of it. The following (BNC) examples illustrate:

(17) (a) Since you're moving out anyway, I don't see why you worry.

(b) 'Since you've already saved my life once, I'm sure I'm quite safe!', she retorted at last.

(c) Since you ask me sir I can't think of a single reason.

A second case is when the speaker refers to some facet of herself, such as her thoughts, feelings, or physical state, as the basis for some further remark, as in the following (BNC) examples:

(18) (a) Since I am a short, plump, Asian young woman, with glasses and shortish hair, I've never found an advert with a woman looking anything like me.

(b) Since I've got no idea why you wanted to see me, you'd better tell me what's on your mind.

(c) Since I know who you are and you obviously know me, there's no need for introductions.

Note that the information in the since-clauses may actually be 'new' to the hearer. From the speaker's perspective, however, the information is beyond dispute; the speaker is, after all, the ultimate authority on matters pertaining to herself.

\subsection{The differentiation of causal relations}

A striking fact about English (and no doubt other languages) is the large number of resources that are available for the expression of relations of cause/reason. In addition to since and because, causal connectives, in English, include such items as so, as, for, therefore, consequently, that's why, for this reason, due to the fact that, and many more. Some of these, such as because, can be regarded as 'pure' causals, while others, such as since and as, are polysemous between causal and diachronically older noncausal readings. In addition, there are quite a few resources which, while not inherently causal, may conventionally or conversationally implicate causality. Consider the temporal relations in the following examples (Traugott \& König 1991: 194-7). Probably, (19a) would be interpreted to mean that hearing the lecture caused us to feel inspired.

(19) (a) After we heard the lecture we felt greatly inspired.

(b) I can't sleep now that I'm alone.

(c) The minute John joined our team, things started to go wrong. 
Consider also the interpretation of participial clauses, as in the following BNC examples.

(20) (a) Having known her for less than two months, he was not yet confident of any strong hold on her affections.

(b) The weather being as it is, she'll no doubt remain there overnight.

(c) the easily accessible position of the Malverns near big population centres make them a popular target for picnickers and day trippers... This being the case, summer weekends are not the best time to visit.

(d) Given that there are several ways of doing a calculation, we can ask which of them, if any, is analogous to the way the brain performs the same calculation.

The information in the participial clauses is backgrounded and presupposed, and in the above examples is likely to be construed as justifying or legitimizing the assertions in the main clauses. Interestingly, in (20d), the presupposed information is explicitly characterized as 'given'.

The various connectives available to an English speaker differ in a number of ways. These include the sequence in which S1 and S2 must be or are typically stated, which of the two clauses is prefaced by a connective, whether the causal relation can be focused, and whether the connective has the status of a subordinating conjunction or is more adverbial in nature. Semantically, as we have seen, connectives are differentiated according to the external or internal status of the causal relation, also with respect to various aspects of subjectivity. The large number of resources available to an English speaker very likely reflects the semantic differentiation of the causal relation itself.

In spite, then, of our earlier remarks that seeing as though appeared to have roughly the same semantic value as other expressions, such as since and seeing that, we might expect these connectives to be associated with somewhat different, or at least only partially overlapping, conditions of use. To investigate this matter we proceeded to draw up a semantic profile of seeing as though. We performed parallel analyses on two other connectives for purposes of comparison and contrast, in the hope of pinpointing specific factors which might motivate the use of seeing as though. Since was selected as it is probably the most general member of the since-type category. Seeing that was selected because of its sharing of lexical material with seeing as though.

For this purpose we compiled a small database consisting of 50 instances each of seeing as though, since, and seeing that. As already mentioned, seeing as though is very sparsely represented in the BNC. We therefore assembled examples on the basis of Google search results. Rather than taking the first 50 hits, we sampled Google returns at intervals of 100 , selecting the first 10 results at each interval. In most cases we retrieved the web page and included the surrounding context in the database. Repeated hits (which were very few) were ignored, as were fragmentary examples where the syntactic affiliation of the seeing as though clause was not clear. Where a web page contained more than one instance of the expression we included only the first. In order to safeguard comparability of data, examples of seeing that and since were also sourced from the Web using the procedure described above. Inappropriate hits (e.g. temporal since) were of course ignored. 
Table 1. Subject of reason clause (r/c) and consequent clause (c/c)

\begin{tabular}{|c|c|c|c|c|c|c|}
\hline & \multicolumn{2}{|c|}{ Seeing as though } & \multicolumn{2}{|c|}{ Seeing that } & \multicolumn{2}{|c|}{ Since } \\
\hline & $\mathrm{r} / \mathrm{c}$ & $\mathrm{c} / \mathrm{c}$ & $\mathrm{r} / \mathrm{c}$ & $\mathrm{c} / \mathrm{c}$ & $\mathrm{r} / \mathrm{c}$ & $\mathrm{c} / \mathrm{c}$ \\
\hline $1^{\text {st }}$ & 15 & 23 & 3 & 10 & 4 & 15 \\
\hline $2^{\text {nd }}$ & 0 & 2 & 0 & 4 & 4 & 6 \\
\hline $3^{\text {rd }}$ (human) & 13 & 13 & 22 & 27 & 13 & 11 \\
\hline $3^{\text {rd }}$ (others) & 22 & 12 & 25 & 9 & 29 & 18 \\
\hline
\end{tabular}

Note: Differences in the 'speaker-centredness' of three connectives are extremely significant; $\chi^{2}(2)=14.600, p=0.0007$.

\section{A semantic profile of seeing as though}

The data were analysed according to criteria which our previous discussion suggested might be relevant to the characterization of the connectives, concerning, in particular, manifestations of subjectivity. The criteria, and our findings, are discussed below.

\subsection{Clausal subjects}

A first, general indication of the subjectivity of a causal construction can be gained by considering what each of the two clauses is 'about'. We take it that clauses which are about the speaker, her opinions, thoughts, and decisions, her recent experiences or her past history, are inherently more subjective than reports about third parties or descriptions of 'objective' states of affairs (Scheibman, 2002).

A simple measure of what a clause is about is to consider the category of the grammatical subject, whether first person ( $I$ or we), second person, or, if third person, whether human or other (animate or abstract). For this purpose we ignored the contribution of 'main clause' expressions of the speaker's epistemic stance; thus, in (21a), we took the subject of I think this place will get some good business to be 'this place', on the grounds that the expression makes an assertion about the place, not about the speaker (cf. Diessel \& Tomasello 2001; Halliday 1985: 333; Verhagen 2005). ${ }^{12}$ We also ignored the effects of focusing and extraposition. Thus, in (21b), we took the subject of the focused clause to be he.

(21) (a) It's only a small store, but I think this place will get some good business, especially seeing as though the over-priced Debacle is directly opposite.

(b) thats what i think he will do this week after around 20 minutes of the game (seeing as though he has mellars coming off the bench).

Results are summarized in table 1. Note that in almost half the seeing as though data the consequent clause is about the speaker. The figures for the reason clause

12 This is confirmed by the question tag test (Halliday 1985: 333), which shows that the 'proposition' expressed in (i) concerns 'this place', not 'I'.

(i) I think this place will get some good business, \{won't it?/*don't I?\} 
are somewhat lower, yet markedly higher than for the two other connectives. On this measure, seeing as though constructions turn out to be more speaker-centred than the other types. The data suggest that seeing that is the least speaker-centred of the three expressions, with since having an intermediate value. On the other hand, since would appear to be the preferred option when a causal construction is about nonhuman (including inanimate and abstract) entities.

\subsection{The content of the reason clause}

We noted earlier (section 4.2) that subordinated reason clauses are likely to contain information which the speaker assumes as given and which is invoked to justify, or explain, the contents of the consequent clause.

Initially, we had intended to classify the contents of the reason clauses according to their information status, whether common ground or newly asserted. We quickly discovered that decisions in this regard were often variable and unstable. We therefore turned to more 'objective' criteria of analysis.

First, we identified those reason clauses whose content pertains to some aspect of the speaker herself, such as her mental or physical state, her recent experiences, or her past history. Although the content of such clauses might well constitute 'new' information to the hearer (the hearer might be ignorant of the speaker's age or of her activities in the recent past), the information is, for the speaker, irrefutable; as such, it is able to constitute an unassailable basis for the content of the main clause.

About one-third of the seeing as though clauses (table 2) fell into the speaker-centred category. The following examples illustrate:

(22) (a) now all this may seem childish from another viewpoint and i assure you it is, but seeing as though $i$ cannot post on the forum they have free range to slander me without reprisal.

(b) The financial person said if we wanted to carry on paying the $£ 40$ a month, we could have the money in years to come, which by the way should have been on the 4th of July this year. Seeing as though we hadn't missed the $£ 40$ we decided to carry on with it for 8 more years, at the end we should be getting $£ 6,000$.

(c) I don't remember that series seeing as though I was only 3 years old at the time.

The seeing that data contain only a couple of comparable examples, of which (23a) is one. There were, in addition, two seeing that examples which report another's selfreference, as in (23b).

(23) (a) I'm not saying I'm different or better than these people - I do the corporate stuff every day too. But, seeing that I do run K10k with Toke, I can honestly say that we're at least trying to be different - and trying to feature things from people who don't mind breaking all the rules.

(b) Wherefore will ye die, O ye house of Israel, seeing that I have no pleasure in the death of him that dieth, saith the Lord God? 
Since-clauses, on this measure, again occupy an intermediate position, with five examples where the speaker appeals to her present situation and three which refer to her past history.

(24) (a) Also, since I know that the author of the strip hangs around S_D - have we corrupted another soul?!

(b) ... since I have encountered apparent skepticism from certain individuals who were only aware of parts of the story, I have decided that it is best to reveal pretty much everything.

A second category concerned those reason clauses which pertain to some aspect of the discourse context, such as the behaviour, attitude, or recent remarks of the listener, matters concerning persons or things currently under discussion, or aspects of the extralinguistic context (such as the weather or the approaching holidays). The information in these clauses might reasonably be regarded as given, or at least easily accessible or retrievable, from the perspective of the speaker and other speech act participants. However, we prefer to emphasize the status of this information as being anchored in the speech act situation.

On this measure the three connectives are roughly comparable (though seeing that scores a little lower than the other two). In (25a), the reason clause refers to some feature of a display available to the addressee and which forms the basis for the speaker's instruction; (25b) refers to some aspect of the current discourse; while (25c) draws attention to some feature of the environment.

(25) (a) Park yourself in the Piper Malibu at Brisbane International Airport (YBBN), and find your GPS. The route we will be taking today is CG ENTRA YSSY. Seeing as though the first waypoint on the list is CG (it's a VOR to save you some time), press the VOR button on the GPS and enter 'CG'. It should say 'Coolangatta' on the GPS screen now.

(b) Seeing as though this is a broad topic, we went with questions instead of key messages.

(c) It's only a small store, but I think this place will get some good business, especially seeing as though the over-priced Debacle is directly opposite.

Here are some comparable examples with seeing that and since.

(26) (a) Seeing that the winter holidays are coming up, what would all of you like to get?

(b) If either of the first two possible courses of action had been taken, it's a safe bet that the probability of this turning into a viable project are almost nil. By remaining flexible and seeing that there are many different ways this situation could play out, you save yourself a great deal of self-induced stress.

(27) (a) Given you have a browser capable of displaying flash and a working internet connection (assumed, since you're reading this), you can check out a Mii maker.

(b) since this survey is now restricting itself, in the modern period, almost completely to Czech-language writing, we must really only mention him here in passing. 
Table 2. The source of the information in the reason clause: (a) the speaker's mental or physical state, (b) some facet of current situation, (c) matters not covered by these categories

\begin{tabular}{llcc}
\hline \hline & Seeing as though & Seeing that & Since \\
\hline Speaker-related & 17 & 4 & 8 \\
Situation-related & 18 & 13 & 17 \\
Other & 15 & 33 & 25 \\
\hline \hline
\end{tabular}

Note: Differences in the speaker-relatedness of the three connectives are significant: $\chi^{2}$ $(2)=9.172, p=0.0102$.

For the sake of comparison, we cite some of the examples which were included in the category 'other' of table 2, where the reason clause pertained neither to the speaker nor to features of the current discourse.

(28) (a) Seeing as though veterinary and health services are generally weak, the avian flu has already resulted in 6 fatal cases since 2005 in Cambodia.

(b) Because we've decided that huge sums of money are seemingly miraculous, and seeing as though the chances of winning the lottery is about 1 in 25 million, we could suppose that our chances of being part of a miracle is about $0.000004 \%$.

(29) (a) Seeing that lawyers have squeezed every drop of live [sic] out of doctors, they need a new target.

(b) Uesbeck and Topp studied the feeding performance in Oniscus asellus; it is an important subject which is now studied by several authors, seeing that isopods are a common component in the soil fauna and are known to feed on a variety of decaying plant material...

(30) (a) Starting the series in 1987 was an unfortunate choice, since the late 1980s and early 1990s was a difficult time for the world's poor.

(b) You will be able to find cheaper inspectors, but some may have very little experience since state licensing does not require any actual home inspection experience.

In many of these cases, to be sure, the content of the clause might plausibly be regarded as constituting common knowledge shared by speaker and hearer, and presented by the speaker to bolster the content of the consequent clause. However, as noted above, a decision regarding the actual status of the information (as shared or new) is a tricky matter and difficult to decide conclusively. The point about these examples, rather, is that the content is not specifically tied to the particular circumstances of the speech act. To this extent, the examples are anchored in the speech situation to a lesser degree than those cited in (22)-(27).

\subsection{The status of the consequent clause}

The dominant function of consequent clauses in seeing as though constructions is to express the speaker's epistemic stance and/or the speaker's attitude. Almost two-thirds 
(30 examples) fell into this category. The clauses expressed the speaker's opinion (8 examples), an evaluation (6), a decision (6), or a suggestion (2). A further 8 examples contained an inference drawn by the speaker, often in association with a modal element (seem, must, etc.). As will be apparent from the following examples, the speaker's opinion, inference, etc. arose from considerations raised in the reason clause.

(31) (a) Merima and I are livid with the fact that we have to leave in a week. Our petition for citizenship will not go in the direction we hoped. I guess I will finally have to really learn the language, seeing as though the only way I will be able to become a citizen, is to get married.

(b) According to Microsoft one of the major benefits of using WPF is the improved designer-developer workflow. But seeing as though WPF is still in its infancy, it's somewhat confusing as to how exactly designers should be working and in what tools.

(c) I decided to have a look around for some clothes, seeing as though they had a special on ladies wear.

(d) Seeing as though every ZVM is still under warranty, Im sure you could get yourself a new one.

In addition, there was one example where the speaker issues an instruction to the hearer (25a), and three examples where the speaker raises a query, as in the following:

(32) (a) Seeing as though Exetel resell Optus, does that mean i can get Optus DSL Direct in October?

(b) I've heard that Switzerland and the US both have possible surprise teams, so good luck to them! And of course, even Roony-less, England is always a big contender, so I hope they do well. Well - seeing as though I support 5 teams, is it possible that 2 out of five make it to the end?? We'll see!!

In the remaining 16 examples in the seeing as though database, the main clause did not contain any overt expression of the speaker's epistemic stance, nor any modal or evaluative elements. Rather, the clause merely stated a fact, reported an event, or described a situation, with the reason clause offering a justification, explanation, or background information relevant to the assertion.

(33) (a) Dad and $i$ headed out to the lakehouse at like 9:45 seeing as though i dont eat breakfast. i was already packed and ready to go with the iPod so we were off.

(b) Seeing as though my parents now live in the United States (I'm gonna rope em into buying me a PSP while they are there and post it back $(-)$ ) and I have been left in this huge ass home by myself, a mate of mine has moved in and brought his PS2 with him.

(34) (a) The River Neckinger flows into the Thames at St Saviour's. The name means 'devil's necktie' - or hangman's noose, seeing as though the dock is opposite an ancient execution site for Thames pirates.

(b) The avian flu in Cambodia not only threatens $75 \%$ of the population relying on subsistence farming, but also poses an immediate danger to those susceptible to this possible pandemic. Seeing as though veterinary and health services are generally weak, the avian flu has already resulted in 6 fatal cases since 2005 in Cambodia. 
The examples in (34) are especially interesting, in that they are the only examples in the seeing as though database which might possibly be said to involve an 'objective' causal relation, between circumstances that hold in the external world and which do not involve human agents. Thus, (34a) explains the name by reference to the location, while (34b) relates the mortality rate to the state of the health services. Nevertheless, we do perceive a subjective nuance in these examples. In (34a) the speaker seems to be suggesting that the name is a suitable one, given the historical background. The speaker, in other words, is offering an implicit evaluation of the appropriateness of the name and the validity of its supposed etymology. In (34b) we also detect the speaker's attitude, especially in the use of the adverbial already. It is as if the speaker is not really surprised that as many as six people have died, given the facts already stated.

Turning to the seeing that data, we again find a substantial number of examples where the main clause has a strongly subjective element. These comprised evaluations (5), opinions (3), decisions (1), suggestions (1), and queries (4).

(35) (a) Seeing that human destructive activity is accelerating I am in favor of Nature bringing a swift end to the oil industry.

(b) Seeing that a lot of these reviews are before the digitaldom that we live in now, I wanted to chime in about this lens and the Canon 10D.

(c) Seeing that the 'blogosphere' is so important, apparently, according to everything I've read, I've been remarkably remiss.

There were, however, several examples of inferences, evaluations, etc. which lacked the strongly speaker-centred subjectivity of the above examples. In the examples in (36) the speaker might well endorse the inferences and evaluations. These, however, are presented 'impersonally', and not due specifically to the speaker, but rather are attributed to some generic or bureaucratic entity.

(36) (a) The day is coming when all the religions of the world will unite, for in principle they are one already. There is no need for division, seeing that it is only the outward forms that separate them.

(b) Seeing that the needs for common services will be based on the needs of a given simulation community represented within a federation, it is felt that it is unlikely that a set of common services that would be encompassing enough to meet the anticipated needs of all users could be developed.

(c) People dealing with probate matters in the state of Maine, should be aware of a few important factors which ultimately contribute to the outcome of a given probate experience. The first has to do with understanding the ways that probate procedures work in Maine. This is particularly important seeing that the only way to get through the Maine state probate process is by adhering to the standardized procedures.

Other examples present 'logical' inferences; these pertain to academic or philosophical-theological registers, registers which are not represented at all in the seeing as though data.

(37) (a) Seeing that it is the nature of uniform circular motion to sweep out equal angles at the center in equal times, and given that these angles at the center belong to 
similar circumferences, which are, nevertheless, proportional to their radii, it thus follows that when the planet passes through point $\mathrm{E}$ belonging to the circle whose semi-diameter is SE, then its motion will be slowest.

(b) Death, therefore, the most awful of evils, is nothing to us, seeing that, when we are, death is not come, and, when death is come, we are not.

Another important category, and one which in our data is associated exclusively with seeing that, is found in the context of third-person narratives. A protagonist becomes aware of a state of affairs described in the seeing that clause, and, as a consequence, acts in a certain way. There were in all 14 such examples in our database.

(38) (a) Vario, seeing that his command was not obeyed, became furious, and demanded the instant return of the boat.

(b) Six of the negroes, seeing that their doom was sealed, killed themselves.

(c) Seeing that they are approaching a crater about the size of a football field and covered with large rocks, Armstrong takes over manual control and steers the craft to a smoother spot.

With respect to the since data, we again find a substantial number of examples where the consequent clause is firmly anchored in the speaker's here and now.

(39) (a) Since I feel that lies have been told, and since I have encountered apparent skepticism from certain individuals who were only aware of parts of the story, I have decided that it is best to reveal pretty much everything

(b) Since folks have so much trouble with 'racist', why don't we try 'bigot'?

(c) Since it won't stop raining ... I spent the afternoon finishing up Season 3 of Oz.

However, on the whole, the since data are characterized by a somewhat lower degree of speaker involvement than the seeing as though data and most of the seeing that data. For example, since is used to report other people's inferences:

(40) (a) Analysts say this is significant since it's the first time the stock's been above \$20 since May 2002.

(b) Jenkins says since al-Qaida is now an ideology, the removal of Osama bin Laden would have less effect on the whole terrorist enterprise now than it would have had four or five years ago.

Here there is a divergence between the speaker and the Subject-of-Consciousness responsible for the inference (though, to be sure, the speaker may well sympathize with the view she reports). Notable, once again, are several examples which attribute the inferencing process to a 'generic' or nonspecific agent rather than to any identifiable individual. Thus, the reasoning in the following is taken to be a matter of 'common sense', to be generally accepted.

(41) (a) Since 40 percent of the world's food comes from irrigated land, water shortages can quickly translate into food shortages.

(b) The attitude that women are responsible for adultery and rape is a catalyst for both, since it not only erodes the thin self-restraint of potential male predators, but also reduces the likelihood that women will report the offenders. 
Table 3. The locus of the causal relation between the reason and the consequent clauses

\begin{tabular}{lllc}
\hline \hline & Seeing as though & Seeing that & Since \\
\hline Speaker & 45 & 29 & 29 \\
Protagonist & 2 & 17 & 12 \\
Generic & 3 & 4 & 9 \\
\hline \hline
\end{tabular}

Note: Differences in the speaker-locus of the three connectives misses significance: $\chi^{2}(2)=4.971, p=0.0833$. However, compared to seeing that and since combined, the speaker-locus of seeing as though is significant: $\chi^{2}(1)=4.971, p=0.0258$.

In yet other examples, we can attribute the inference (as well as the evaluative judgement) to the speaker; however, the subject matter is of a nonpersonal nature, having to do with situations in which the speaker is not a participant.

(42) (a) Starting the series in 1987 was an unfortunate choice, since the late 1980s and early 1990s was a difficult time for the world's poor.

(b) Since these Syrian historical flags pages contain basically a compilation of several contributions, there is no way to tell out who reported the 1932-1946 Syrian flag with stars pointing downward.

Not surprisingly, these examples are found in more formal registers (book reviews, political commentaries), rather than the highly personalized blogs, chatrooms, and the like which are typical of most of the seeing as though data.

\subsection{Locus of causal relation}

Here we considered the 'locus' of the causal relation, that is, the agent who is responsible for establishing the relation between the two clauses, whether the speaker, a protagonist other than the speaking subject, or a generic, unnamed third party.

As our earlier discussion in section 4.2 showed, alternative interpretations of causal constructions are often possible. She left the party because it was getting late (11b) most likely reports a causal relation established by the protagonist. Even here, though, a more subjective interpretation can be envisaged, in which it is the speaker who adduces the reason for the person's departure. In evaluating this aspect of our data we chose what we took to be the most plausible or natural reading of the examples; we did not attempt to coerce a more subjective interpretation.

The results (table 3) confirm the trends reported so far. Seeing as though is used almost exclusively to express a relation established by the speaker, only rarely to state an 'objective' relation attributable to a generic third party, as in (34), or to report a relation established by a third-person protagonist. Thus, (43) is most plausibly taken to attribute the reason relation to Biggie, rather than to the speaker (though the latter interpretation, to be sure, cannot be ruled out). 
Table 4. Incidence of overt expressions of stance (e.g. I think) and other stance expressions (e.g. probably)

\begin{tabular}{lccc}
\hline \hline & Seeing as though & Seeing that & Since \\
\hline Overt epistemic stance & & & \\
Of speaker & 23 & 11 & 7 \\
Of addressee & 0 & 0 & 1 \\
Of protagonist & 2 & 2 & 2 \\
Other stance expressions & & 34 & \\
$\quad$ Speaker-oriented & 38 & 0 & 25 \\
$\quad$ Protagonist-oriented & 2 & 34 \\
\hline \hline
\end{tabular}

Note: Differences between the three connectives with respect to expressions of overt epistemic stance are significant: $\chi^{2}(2)=7.875, p=0.195$, as are the differences with respect to all stance expressions: $\chi^{2}(2)=8.107, \mathrm{p}=0.0174$.

(43) Biggie wanted to start a clothing line that would cater to 'Big' men like himself, seeing as though it was hard to find the quality of clothing he admired.

The seeing that data contained a significant number of examples where the relation is attributed to a named protagonist, as in the narrative examples cited in (38). The since data, on the other hand, scored highest for a generic, impersonal, or bureaucratic locus.

\subsection{Expression of speaker stance}

Next we considered overt markers of the speaker's epistemic stance, such as I think, I suppose, it seems to me, and the like, whether in the consequent clause or in the reason clause (cf. Mortelmans 2006). Subcategories concerned the reported epistemic stance of a protagonist or the presumed stance of the addressee. We also counted the number of other stance expressions, such as presumably, probably, really, and the like. We included here epistemic uses of modals such as must, can't, and will, as well as expressions of speaker attitude. Needless to say, one and the same example could contain several instances of these categories.

Seeing as though scored highest on both of these measures, confirming the high degree of subjectivity associated with this connective; since registered the lowest values (table 4).

\subsection{Sequence}

For all three connectives there was a preference for the reason clause to occur before the consequent clause. The preference is strongest for seeing that (35 examples of initial reason clauses), weakest for since (27 examples), with seeing as though occupying an intermediate position (30 examples). The differences are not significant: $\chi^{2}(2)=1.065, p=0.5879$. The overall preference for initial position is consistent 
with the presumed information structure of since-type connectives (section 4.3). In about a third of the cases, however, speakers justified the content of the main clause in a postponed reason clause.

\subsection{Conspectus}

Our discussion has shown that seeing as though constructions are - in Scheibman's (2002: 167) phrase - strongly 'anchored to the speaker'. The reason clause typically states some fact about the speaker, while the consequent clause typically expresses the speaker's opinion, evaluation, decision, etc. Also characteristic of the data is the high incidence of overt expressions of speaker stance and speaker attitude.

Elements of subjectivity are not, of course, absent from the two other data sets we analysed. Indeed, one conclusion could be that there is considerable overlap in the usage range of the three expressions. Some of the examples with since and seeing that would, it seems to us, be quite acceptable with seeing as though, particularly when they exhibit the various kinds of subjectivity associated with seeing as though. Conversely, since could probably serve as an adequate replacement for many of the examples with the other two connectives. Nevertheless, the data do point to a certain degree of specialization. Since seems to be preferred when the speaker takes a somewhat detached perspective on the relation, reporting other people's inferences or attributing general validity to the relation. Seeing that, on the other hand, has a specialized use in narrative reports, presenting the perspective of one of the protagonists.

In light of these observations, it is instructive to return to the student's email which triggered this study. Replacing the student's seeing as though with since would, we feel, dramatically change the tone of the communication. The student would no longer be making a tentative suggestion, but a peremptory request.

(44) Dr X could supervise my thesis, $\{$ seeing as though/since $\}$ she is a native speaker of German.

The difference, we suggest, arises from the status of the relation between Dr X's being a native speaker of German and her suitability to supervise a thesis on the German language. Seeing as though attributes the relation to the writer and her construal of the situation, while since suggests that the relation has more general validity. In the first case, the validity of the causal relation is contestable; in the second case it is not. ${ }^{13}$

\section{Seeing (that)}

One of the things that fascinated us about seeing as though was the internal structure of the expression. How come as though can combine with seeing to create a reason

13 Elizabeth Traugott (p.c.) raised the question of how the writer of the email could have expressed herself, in a pragmatically appropriate manner, if she had chosen to avoid seeing as though. Probably, some modalized formulation would have been used, such as ' $\mathrm{Dr} \mathrm{X}$ is a native speaker of German. So in view of that I guess she might be a good choice of supervisor. However, ...'. 
connective? In light of our foregoing discussion, a second question is: why should this expression be associated with highly subjective contexts? We approach this matter by first considering the use of seeing in reason expressions.

According to a common conceptual metaphor (Lakoff \& Johnson 1999: 53-4), KNOWING IS SEEING. The metaphor underlies such everyday expressions as I see what you mean, where the acquisition of knowledge is spoken about in terms of visual perception (Sweetser 1990). The experiential basis of the metaphor is clear: if you see (with your own eyes) that something is the case, you have good reason for believing that it is the case. Moreover, if you see something, others nearby can presumably also see it; the knowledge gained thereby is shared and can be taken for granted by the speech participants. The KNOWING IS SEEING metaphor thus lends itself to the designation of given information, which can be the basis of some further assertion or inference. ${ }^{14}$ The causal sense is exhibited by the connective in view of (the fact that), as well as, of course, by seeing that. Comparable expressions (though with a past, not present participle) exist in Italian (visto che), French (vu que), and Dutch (aangezien, gezien dat).

There are several aspects to the development of causal seeing that. Consider, first, the following (BNC) examples.

(45) (a) Seeing that he had now regained consciousness, Sarah murmured, 'Thank God.'

(b) Seeing that he had frightened her, Mungo tried to soften the blow.

(c) In the mid-1960s the Kremlin, seeing that the economic system was not working, briefly flirted with the idea.

(d) Well, he said that he wanted to do something useful with his life, seeing that it had been given back to him when he hadn't expected it.

The visual sense of see is prominent in (45a). Like the participial clauses in (20), however, (45a) is also amenable to a causal interpretation: as a consequence of her having seen (and thereby having learned) that 'he' had regained consciousness, Sarah murmured... In the remaining examples in (45) the visual component is gradually weakened and the metaphorical value of seeing becomes more prominent. The malfunctioning of an economic system (45c) is not something to be perceived through the eyes; the Kremlin (or, to unpack the metonymy, officials in the Kremlin) came to know that the system was not working, and this was the reason for their subsequent decisions.

In the above examples, seeing is a participle, whose understood subject is the subject NP of the main clause. (Failure to follow this principle results in the grammatical solecism of the 'dangling participle'.) In (45a) it is Sarah who saw, and thereby learned, that the other person had regained consciousness, while in $(45 \mathrm{c})$ it is the Kremlin which 'saw' (i.e. learned) that the economic system was not working. In the following,

14 The KNOWING IS SEEING metaphor is common in Indo-European languages, but is by no means universal (Evans \& Wilkins 2000). Discussion of the metaphor in e.g. Sweetser (1990) has focused on the development of see as an expression of understanding, not on its role in the development of reason connectives. 
however, the understood subject of seeing cannot be identified with the grammatical subject of the main clause.

(46) (a) Doubtless it included rent from Garsington as well as from the Whitchurch glebe, which must have been let to farm seeing that his own agricultural interests were limited to a couple of dozen sheep and some poultry.

(b) It is hard enough for me to run my practice here, seeing that I am that strange animal, a gentleman

(c) Thinking about our coastline, seeing that we're talking about it a bit, what about our white cliffs all along the coast?

Who, then, is doing the 'seeing' in these examples? In (46a) it could be a participant in the situation, namely, the person whose agricultural interests are mentioned. In (b) and (c), the relevant participant is, presumably, the speaker. The same, actually, might be true for some of the examples in (45). In (45c) it could be the speaker, not the Kremlin, who presents the Kremlin's 'flirting with the idea' as resulting from the bad economic situation, while ( $45 \mathrm{~d}$ ) could be interpreted to mean that it was the speaker who is proposing a reason for the protagonist's assertion. In these cases, it might be actually inappropriate to speak of an 'understood subject' at all. Seeing that is better analysed as a conjunction, not as a participle (Hopper 1991: 30-1), a conjunction, moreover, which locates the causal relation with the speaker, not with a participant in the designated situation.

Our data on seeing that, discussed in section 5, display the various stages of the grammaticalization process discussed above. In about one-third of the examples, seeing that preserves its participial character; these include the 14 narrative examples in which a protagonist 'saw' (i.e. became aware of) a certain situation and then acted accordingly. But the data also include examples of more advanced grammaticalization, in which the causal relation is attributable to the speaking agent, or at least to a generic subject. Interestingly, the advanced stage is already illustrated by the early $O E D$ examples cited in (3).

\section{7 (Seeing) as though}

Having traced the development of seeing into a conjunction of reason, we now turn to the occurrence of as though in the reason connective.

Formally, seeing as though looks like a participial construction, headed by seeing and with as though functioning as a kind of complementizer. An immediate problem with this analysis is that nonparticipial forms do not exist: there is no ${ }^{*} I$ saw as though, * to see as though, etc. Even the past form having seen as though is not attested. In fact, none of the seeing as though examples in our database can plausibly be analysed as participles, whereby an unexpressed subject - the entity which does the 'seeing as though' - can be identified with the subject of the main clause.

This suggests that seeing as though is a compound expression, which cannot be analysed as a compositional function of its parts. Such a conclusion is not outrageous, 
since the same goes for as though itself. Consider the situation in which two as though clauses are coordinated:

(47) It was as though I had been there before and *(as) though everyone knew me.

While the second occurrence of as though is optional, it is not possible to omit only the second occurrence of as. We cannot, therefore, identify two though-phrases in (47), dependent on as. Huddleston \& Pullum et al. (2002: 1151) argue on similar grounds for the compound status of as if, pointing out that the expression cannot be analysed in terms of an if-phrase headed by as.

We can apply a similar argument to seeing as though. As a matter of fact, we have not been able to source any examples of coordinated seeing as though clauses. On our intuitions, however, the invented example in (48a) - which is based on (31c) - sounds horribly ungrammatical with the second occurrence of seeing omitted. On the other hand, the omission of seeing seems perfectly acceptable with coordinated seeing that clauses, indicative of the constituent status of the that-clauses.

(48) (a) I decided to have a look around for some clothes, seeing as though they had a special on ladies wear, and *(seeing) as though they generally stock items in my size.

(b) I decided to have a look around for some clothes, seeing that they had a special on ladies wear, and (seeing) that they generally stock items in my size.

While it might be futile to seek a compositional account of seeing as though, it is nevertheless legitimate to ask whether, and in what ways, the presence of as though in the complex conjunction might be motivated.

As though is an established unit in English, used to introduce an irrealis clause. As though, as if, and like are all possible in this context (though conservative speakers might baulk at 'substandard' like):

(49) (a) It was $\{$ as though/as if/like $\}$ I had been there before.

(b) He spoke to me $\{$ as though/as if/like $\}$ he knew me.

If the subordinate clause is realis, only like is possible:

(50) He spoke to me $\left\{{ }^{*}\right.$ as though/*as if/like $\}$ he speaks to everyone else.

These observations seem only to deepen the mystery of seeing as though. The connective introduces a clause whose content is taken by the speaker to be selfevidently true and not at all hypothetical or imaginary. Yet, as shown by (50), as though is incompatible with a clause whose content is presented as corresponding to reality.

Given the distributional equivalence of as though, as if, and like in the contexts in (49), the question arises whether like and as if can also combine with seeing in reason clauses. Recall the student's email which triggered our investigation. On our intuitions, seeing like would be marginally acceptable, seeing as if not at all.

(51) Dr X could supervise my thesis, \{seeing as though/*seeing as if/?seeing like $\}$ she is a native speaker of German. 
As a matter of fact, a Google search returned some possible examples of causal seeing like (no examples were found in the BNC). Of course, in examples such as the following, it is always possible to interpret like as an interpolated discourse marker: Seeing like - you've never experienced... Nevertheless, a causal reading of seeing like is quite compelling.

(52) (a) I can see how you might say that. Seeing like you've never experienced a hamburger.

(b) The daughter said to get rid of it, but seeing like it's a prayer book and all, I don't have the heart to throw it away.

We were initially inclined to regard seeing as if (as a reason connective) as totally ruled out. Anyone familiar with data-based research, however, will be wary of making impressionistic claims about what is impossible or ungrammatical in a language. Google searching (February 2007) returned about 13,000 hits for the combination. The majority of these, to be sure, had a clear syntactic break after seeing, with no possibility of a causal interpretation. Even when seeing as if was compatible with a causal reading, as in (53a), it was possible to imagine a different parsing, with seeing as serving as the reason connective followed by an embedded if-clause: Do the adverts get to you seeing as [if you're bald] it must be annoying? In examples (b)-(d), on the other hand, the alternative parsing would be scarcely possible. These, then, would be genuine examples of seeing as if functioning as a reason connective.

(53) (a) Do the Shane Warne adverts get to you seeing as if you're bald it must be annoying to see someone complain who still has a fair bit?

(b) A correct answer may - or may not - measure intelligence, and seeing as if different test questions seem to highlight different abilities, some people thought it'd be good to come up with a uniform representative of what intelligence may be.

(c) The new one looks ok and I won't degrade it seeing as if none of us has seen it.

(d) So I guess I don't feel so bad about Saturday, seeing as if you weren't feeling well either.

Such uses appear not to be particularly frequent (we had to sift through a hundred Googled hits to find the above examples). Even bearing in mind our earlier strictures concerning search engine frequencies, it is reasonable to propose that causal seeing as if is considerably less frequent than causal seeing as though.

As though and as if are commonly regarded as sharing the same semantic value (e.g. Dancygier \& Sweetser 2005: 228). However, a hint as to their possible differentiation is provided by Huddleston \& Pullum et al. They (2002: 1152) cite the following examples:

(54) (a) He was treated as if he were a Commonwealth citizen.

(b) The gambler turned to the army girl with an odd expression, as though he were remembering painful things. 


\section{They observe:}

The natural interpretation of [54a] is that he was treated like a Commonwealth citizen although he wasn't one really. Example [54b], however, doesn't imply that he wasn't remembering painful things: on the contrary, it suggests that he was, or appeared to be. (Huddleston \& Pullum et al. 2002: 1153)

Their claim, then, is that as if is a true counterfactual: they treated him as they would have treated him if he had been a Commonwealth citizen (which he was not). The association of as if with counterfactuality is confirmed by uses such as the following, where as though would be rather less acceptable:

(55) (a) As if I would try to cheat you!

(b) As if I didn't have enough on my plate as it was!

Counterfactuality no doubt motivates the sarcastic rebuttal As if! (an alternative to the probably more common Yeah right!). The following are from the Urban Dictionary: ${ }^{15}$

(56) (a) If a guy tells me he knows I'm in love with him (but I think he's a total loser), then I say to him 'AS IF!'

(b) the sales guy came up to me, and was like, we have the best polyester pants! and i told him loud and clear 'as if' and then i walked out the door.

While as if is associated with counterfactuality, as though, according to Huddleston $\&$ Pullum et al., focuses on how things appear, and the appearance of things may (but need not) correspond to reality. Assuming, then, that as though is neutral with respect to factuality, the expression would not be incompatible with the role of seeing as though as introducing information taken to be self-evidently true. As if, with its strong counterfactual associations, would be much less appropriate.

We do not want to insist on a categorical distinction between as if and as though. In many contexts - even those in (54) - the two expressions do seem to be interchangeable. Moreover, BNC data suggest that at least some uses of as if are open to the 'appearance' interpretation which Huddleston \& Pullum et al. attribute to as though. Rather than conveying the counterfactuality of 'each marriage was doomed to failure', (57a) suggests that this might well have been the case, or, at least, that this is how things appeared. Similar remarks apply to the other as if examples in (57) and to the as though examples in (58).

(57) (a) With hindsight, it seems as if each marriage was doomed to failure from the start.

(b) It really seems as if some drivers fall prey to a death wish when freezing fog descends.

(c) It looks as if it will have to be withdrawn.

(58) (a) It almost seems as though they shot people for the hell of it

(b) In keeping with the career pattern of your chart, it seems as though money will come in from a variety of sources.

(c) It looks as though he was killed in the south porch of the church.

\footnotetext{
15 Accessed at http://www.urbandictionary.com/.
} 
Let us now take stock. We have established that seeing as though cannot reasonably be analysed, on either semantic or syntactic grounds, as seeing [as though]. At the same time we note that seeing as though is only one of a number of reason conjunctions based on seeing. Not only do we have seeing that, but also (if more rarely) seeing as if and even seeing like. There are, in addition, the expressions documented in section 3, namely, seeing as and seeing as how. Moreover, as though, as if, and like share distributional similarities apart from their occurrence with seeing.

Let us pursue further the question of the distributional equivalence of the items which can co-occur with seeing. Consider, for example, their use as (nonstandard) complementizers introducing reported speech. Alongside standard that, we find as, how, like, and also as how (BNC data):

(59) (a) she said as you had given it to her, sir.

(b) He said how he had noticed the barometer as he passed through the sitting-room.

(c) He said like he'd rehearsed it.

(d) The doctor's telephoned twice and said as how if you weren't back by ten, he'd drive down from London.

We must also mention the recent upsurge in the use of (be) like to introduce direct speech, or, perhaps more accurately, performed speech (Blyth, Rechtenwald \& Wang 1990; Foolen 2001; Macaulay 2001; Winter 2002). The usage is illustrated in (56b), given below as (60a). A recently encountered example is (60b):

(60) (a) the sales guy came up to me, and was like, we have the best polyester pants!

(b) Everybody was like, what are you going to call the dog? ${ }^{16}$

Along with as if and as though, these items can all occur after predicates of seeming and appearing. Example (61a) is invented; (61b) is from the BNC; the others are Googled.

(61) (a) It seemed $\{$ as though/as if/like/that $\}$ he knew me.

(b) But it seemed as how you could become a troopie.

(c) It seemed as she had no arms, just a shell which contoured her feminine form.

(d) seems how she has fleas.

What these various items have in common is that they have to do with how something appears, what it looks like, or how it can be represented. We have already drawn attention to the 'appearance' sense of as though and as if. Consider also the case of as. Amongst the many uses of this highly polysemous word are those relating to similarity, comparison, and appearance. ${ }^{17}$ Thus, (62a) invites a comparison between two events of 'looking over one's shoulder' and conveys the similarity between them; like would also be possible here. On the other hand, $(62 \mathrm{~b})$ has to do with the speaker's image, that is, how the speaker appears, in this case, to himself. This latter sense is particularly

\footnotetext{
16 This is a comment made by Peter Jackson on his plans for a remake of the film The Dam Busters, the issue being that one of the characters in the original film had a dog called Nigger.

17 Amongst its many other uses, as can signal both temporal and causal relations (Broccias 2006; Morris 1996).
} 
in evidence with verbs of evaluation, such as regard (as), consider (as), and see (as) (examples from the COBUILD dictionary).

(62) (a) He looked over his shoulder as Jack had done.

(b) I always thought of myself as a very understanding father.

(c) Do you see English teaching as being principally an education in values?

Returning, now, to causal connectives, we find that various combinations of as and how (and that) can occur with seeing. ${ }^{18}$ The following examples were obtained by Googling. Note that many of these examples, and the ones to be cited subsequently, exhibit the kinds of subjectivity associated with seeing as though. The reason clauses mostly pertain to information about the speaker or hearer, while the consequent clauses are predominantly 'about' the speaker, her attitudes, decisions, or actions.

(63) (a) Seeing as you refuse to understand anything what's the point in trying.

(b) I am kind of sorry if this offends you, seeing as that it is the 'holiest' holiday on the Christian calendar.

(c) Seeing as how this site is open to anyone in the world who wants to visit it and seeing as how I really don't want to be embarrassed by my own public sloppiness, I will use the best English I know (grammar, spelling, capitalization and punctuation).

(d) Seeing how I had a lot of time on my hands, I thought it would be a good time to re-watch the Lord of the Rings trilogy.

(e) I have seen many fires like that seeing how that $i$ am a firefighter and $i$ would know.

(f) Of course, the assumption that Batman has had time to find out who Spawn is and prepare for the fight is a given, seeing as how that he has the minor disadvantage of being mortal.

Googling also turned up the following examples, involving combinations of the above items with as though:

(64) (a) Seeing as though that I know nothing about Judge Roberts except that he may be the second handsomest man on the Court.

(b) I have come across this site completely by accident, but seeing as though as i'm here i thought i'd say hello and post some of my pics for you to share!

(c) I thought I would go to the party and meet a few people seeing how as though I don't know anyone yet.

(d) I need to be giving you encouragement seeing as how though you just lost your father.

(e) I haven't been in the best of moods lately seeing as though how (almost) everything in my life seems to have gone off track.

Not only this, but we find various combinations of how, as, and as though in reason conjunctions with words other than seeing, for example, with since:

${ }^{18}$ Like also participates in these locutions. However, given the problematic parsing of like - see our comments on $(52 a)$ - we exclude this word from the data presented here. 
(65) (a) Since how it's the raining season what outfit could be complete without this: This year's hip hat (\$95) and classic umbrella (\$52).

(b) I had to try to find an apartment and we spent the first two days looking at apartments. Since as how I'm now unemployed and on a student budget I had to look for a place not too close to school.

(c) You choose, since as though you are the one who created the idea.

also with seen:

(66) (a) if you want to achieve the same thing, it might be a little bit challenging, but seen that you're asking great questions like these, I am sure you'll be able to figure it out.

(b) i'd say you were stalking me, seen as how you cycled passed me today in glendale twice when i was with my girlfriend.

(c) Seen as though no one has actually answered your question I thought I might have a go (even though I don't know much about electronics).

and with being:

(67) (a) Being as you are males of the species AND you know a heck of a lot about cars, perhaps you can explain why menfolk tend to give their cars a burst of gas as they turn them off.

(b) told cousin Sally that my wife was poorly, being as how she had a touch of the rheumatics in the hip.

(c) I sorta assumed they meant July 7th, 8th, and 9th being as how that they later said June 7 th ... and that they called it 31 rst St., not once, but twice.

(d) Well, being as though I just recently recuperated from the flu, these first few weeks of the semester haven't exactly been the easiest for me.

as well as with given:

(68) (a) Given how I never bought the last record, you know I'm thrilled by this.

(b) Given how that the two names - Yams and Sweet Potatoes - have become almost interchangeable in popular use, I suspect that someday it will become officially okay to use both names for the same tuber, regardless of the true origin of the Yam.

(c) I certainly don't have any better ideas, given as how I'm not entirely clear on what a credit derivative is.

(d) A.K. is the Brigadier-General and obviously knows the Doctor (one wonders if she may have been introduced by L.S., given as though she seems to know him by repute as well as by person.)

and even with been (!):

(69) (a) I'll just put some random interests here and a little about me, been as you asked so nicely.

(b) Are you sure about that Andy (i only ask been as though you had to double check).

(c) The PC must also have Windows 2000 or XP (including home edition). Been as how most systems have this, I doubt it would be a problem for many. 
A reviewer drew our attention to the same phenomenon with another expression which can (conventionally) evoke causality, considering:

(70) (a) I missed 3 lectures in week 3 of my semester, and it's shocking considering how I've actually only got 4 lectures, 1 lab and 1 tutorial to attend per week

(b) But i did quite well considering as i got 260 or $270+$ trophies

(c) I submitted his picture, and received no response which isn't surprising, considering as how the casting director probably got 500 pictures for that one part, and there were probably forty roles to fill.

(d) Considering as though there are few Nazis in this video, find something else to validate your point.

A number of things seem to be going on here. First, we have a cluster of items which evoke similarity and appearance and which share distributional commonalities in non-causal contexts. These items are all able to occur with causal seeing. What is particularly striking about the data, however, is the role played by constructional blending (Barlow 2000; Fauconnier \& Turner 2002). The blends take as input two expressions with overlapping lexical content and with roughly comparable semantic values. Thus, seeing as that (63b) blends the already established locutions seeing as and seeing that; seeing how as though (64c) blends seeing how and seeing as though. Blending is also at work in the various locutions involving since, being, given, and considering. Here, items which commonly co-occur with causal seeing are found with words which themselves have established uses as reason connectives. Thus, given as though (68d) blends seeing as though and given (that). The examples with seen and been, on the other hand, presumably arise because of the phonological confusion between being and been, seeing and seen. (In rapid speech, the pairs might be virtually indistinguishable). Phonological factors may also be at work elsewhere in the data. Consider the fact that seeing as if appears to be considerably less frequent than seeing as though. This could be because as if is more strongly associated with counterfactuality than as though. The preference for as though could also be due to the phonological overlap between (as) though and the standard complementizer that (both commence with the dental fricative). This suggestion (made to us by a reviewer) is supported, first, by the occurrence of though (not, however, of if) as a complementizer after predicates of seeming and appearing (71), also by its occurrence in yet another causal connective, seeing though (72).

(71) (a) If laws are being broken, and it seems though they are, then the right to publish relevant information is important.

(b) It looks though it could be noisy.

(72) (a) I actually think your lot might do alright next year but that dingo comment was a bit sad, seeing though I wasn't even born when that Chamberlain girl went missing.

(b) Seeing though I'm not aware exactly how big the glass (or empty vegemite jar) I manage to find in the dark will be, that method isn't very helpful to me. 
The above remarks are speculative and many questions remain open. One is, why this extraordinary proliferation of new resources for the expression of causal relations? The creative exuberance manifested by our data is not, to be sure, unique to this domain. It is observed in the constant renewal of intensifiers, euphemisms, modals and semimodals, and even quotatives. These are prime sites for a speaker's 'self-expression' (Bolinger 1972; Hopper \& Traugott 1983; Rickford, Wasow, Zwicky \& Buchstaller 2007; Vandelanotte 2004). The 'fevered invention' (Bolinger 1972: 18) which we observe in our data could well be driven by the inherent subjectivity of causal relations, and the highly speaker-centred nature of the relations conveyed by seeing as though and its variants.

A second question concerns the mechanisms for innovation which the data exemplify. Lexical blending is a well-known and well-studied phenomenon (Kemmer 2003). How widespread, however, is the process of constructional blending, of the kind that we have reported? We cannot go into this issue here. We would, though, like to cite just one example, concerning quotatives. We have already mentioned quotative (be) like. Rickford et al. (2007) document the emergence, in recent times, of two new quotatives, (be) all and (be) all like.

(73) (a) And she's like, 'Afraid so'

(b) I kinda teased him, I'm all 'wow you must reaaaaaally need attention back there....'

(c) And she's all like, 'Well you HAVE to. Are you allergic to them?'

All like can be regarded as a blend of already existing locutions. Quotative all and like are 'stacked', just as how and as though are stacked in (64c).

\section{Conclusion}

This article has addressed a new, and to our knowledge previously unstudied, reason connective in English, seeing as though. The expression attracted our interest, firstly, because of its seemingly noncompositional structure.

English speakers already have at their disposal a large palette of resources for the expression of reason relations. Why should they have felt the need to innovate in this domain?

We approached these questions on a number of fronts. First, we drew up a semantic profile of seeing as though, with the aim of possibly differentiating the expression from other connectives with which it might be in competition. Our principal finding was that seeing as though is associated with highly subjective, or speaker-centred, construals of the reason relation. Typically, the expression introduces information pertaining to the speaker or to the current discourse context. The information is the basis for a query, suggestion, decision, or inference entertained by the speaker. Importantly, the causal relation is established by the speaker; it is not, usually, accorded general 
validity. To this extent, seeing as though fills a niche within the paradigm of causal connectives.

With respect to the construction's internal structure, we examined the use of seeing in reason connectives against the background of the conceptual metaphor KNOWING IS SEEING. We also confirmed that, on both syntactic and semantic grounds, seeing as though cannot be analysed compositionally, as [seeing [as though]]. We noted, however, that the items which are able to occur with causal seeing - as, how, as how, like, as though, and even as if - share distributional equivalences in other contexts, for example, as introducers of direct and indirect speech and as complementizers after verbs of seeming and appearing. The semantic commonality of these items, having to do with how things appear or can be represented, meshes well with the subjectivity of the causal relations encoded by seeing. We also noted that various combinations and permutations of these items are able to co-occur with seeing; seeing as though turned out to be only one of a large number of innovative connectives based on seeing. Not only this, but the various items are able to occur (in informal contexts, to be sure) with other items associated with causality, such as since, given, being, and considering. We suggested constructional blending as the appropriate theoretical device to handle this phenomenon.

Kortmann (1997: 331) remarked on a general reduction in the inventory of subordinators (including clausal subordinators) in Present-day English as compared with Early Modern English. For Early Modern English he lists, as causal conjunctions, as, seeing (that), being (that, as), for, because, in respect (that), and whiles (that). Curiously, only as and seeing (that, how) are listed for Present-day English, the others, according to Kortmann, having 'dropped out of use'. Kortmann also notes that Present-day English exhibits a low level of innovation with respect to earlier periods. The data reported in this article offer a different perspective. Not only has a new resource (as though) been co-opted for the expression of the reason relation, we also witness, in the blogosphere and in informal registers more generally, an exuberant proliferation of new forms created through the combination and blending of existing forms. In this article we hope to have made a start in studying this extraordinary development.

Authors' addresses:

Linguistics Programme

Department of English

University of Otago

Dunedin

New Zealand

john.taylor@stonebow.otago.ac.nz

Department of English

University of Macau

Macau SAR

kpang@umac.mo 


\section{References}

Altenberg, B. 1984. Causal linking in spoken and written English. Studia Linguistica 38, 20-69.

Ammer, C. 1997. The American heritage dictionary of idioms. Boston: Houghton Mifflin.

Athanasiadou, A., C. Canakis \& B. Cornillie (eds.). 2006. Subjectification: Various paths to subjectivity. Berlin: Mouton de Gruyter.

Barlow, M. 2000. Usage, blends, and grammar. In M. Barlow \& S. Kemmer (eds.), Usage based models of language. Stanford: CSLI publications. 315-45.

Biber, D., S. Johansson, G. Leech, S. Conrad \& E. Finegan. 1999. Longman grammar of spoken and written English. London: Pearson.

Blythe, C., S. Recktenwald \& J. Wang. 1990. I'm like, 'Say what?!': A new quotative in American oral narrative. American Speech 65, 215-27.

Bolinger, D. 1972. Degree words. The Hague: Mouton.

Broccias, C. 2006. The construal of simultaneity in English with special reference to asclauses. Annual Review of Cognitive Linguistics 4, 97-133.

Couper-Kuhlen, E. \& B. Kortmann (eds.). 2000. Cause - condition - concession - contrast: Cognitive and discourse perspectives. Berlin: Mouton de Gruyter.

Dancygier, B. \& E. Sweetser. 2000. Constructions with if, since, and because: causality, epistemic stance, and clause order. In Couper-Kuhlen \& Kortmann (eds.). 111-42.

Dancygier, B. \& E. Sweetser. 2005. Mental spaces in grammar: Conditional constructions. Cambridge: Cambridge University Press.

de Smet, H. \& J. C. Verstraete. 2006. Coming to terms with subjectivity. Cognitive Linguistics 17, 365-92.

Diessel, H. 2001. The ordering distribution of main and adverbial clauses: A typological study. Language 77, 433-55.

Diessel, H. 2005. Competing motivations for the ordering of main and adverbial clauses. Linguistics 43, 449-70.

Diessel, H. \& M. Tomasello. 2001. The acquisition of finite complement clauses in English: A corpus-based analysis. Cognitive Linguistics 12, 97-141.

Evans, N. \& D. Wilkins. 2000. In the mind's ear: The semantic extensions of perception verbs in Australian languages. Language 76, 546-92.

Fauconnier, G. \& M. Turner. 2002. The way we think: Conceptual blending and the mind's hidden complexities. New York: Basic Books.

Finegan, E. 1995. Subjectivity and subjectification: An introduction. In Stein and Wright (eds.). 1-15.

Foolen, A. 2001. Quotative markers in English and other languages: Construction Grammar meets Interactional Linguistics. Paper presented at ICLC 7, Santa Barbara, 26 July 2001.

Ford, C. 1993. Grammar in interaction: Adverbial clauses in American English conversations. Cambridge: Cambridge University Press.

Goldberg, A. 1995. Constructions. Chicago: University of Chicago Press.

Halliday, M. 1985. An introduction to functional grammar. London: Edward Arnold.

Halliday, M. \& R. Hasan. 1976. Cohesion in English. London: Longman.

Hopper, P. 1991. On some principles of grammaticization. In Traugott \& Heine (eds.). 17-35.

Hopper, P. \& E. Traugott. 1983. Grammaticalization. Cambridge: Cambridge University Press.

Huddleston, R. \& G. Pullum et al. 2002. The Cambridge grammar of the English language. Cambridge: Cambridge University Press.

Keller, F., M. Lapata \& O. Ourioupina. 2002. Using the web to overcome data sparseness. In J. Hajič \& Y. Matsumoto (eds.), Proceedings of the conference on empirical methods in natural language processing. Philadelphia: EMNLP. 230-7. Available at http://homepages. inf.ed.ac.uk/mlap/Papers/emnlp02.pdf. 
Keller, R. 1995. The epistemic weil. In Stein \& Wright (eds.). 16-30.

Kemmer, S. 2003. Schemas and lexical blends. In H. Cuyckens, T. Berg, R. Dirven \& K.-U. Panther (eds.), Motivation in language. Amsterdam: Benjamins. 69-97.

Kilgarriff, A. \& G. Grefenstette. 2003. Introduction to the special issue on the web as corpus. Computational Linguistics 29, 333-47.

Kortmann, B. 1997. Adverbial subordination: A typology and history of adverbial subordinators based on European languages. Berlin: Mouton de Gruyter.

Lakoff, G. \& M. Johnson. 1980. Metaphors we live by. Chicago: University of Chicago Press.

Lakoff, G. \& M. Johnson. 1999. Philosophy in the flesh. New York: Basic Books.

Langacker, R. 1987. Foundations of cognitive grammar, vol. 1: Theoretical prerequisites. Stanford: Stanford University Press.

Lewis, D. 1973. Causation. Journal of Philosophy 70, 556-67.

Lyons, J. 1981. Language, meaning and context. London: Fontana.

Lyons, J. 1982. Deixis and subjectivity: Loquor, ergo sum? In R. Jarvella \& W. Klein (eds.), Speech, place and action: Studies in deixis and related topics. New York: Wiley. 101-24.

Lyons, J. 1995. Linguistic semantics: An introduction. Cambridge: Cambridge University Press.

Macaulay, R. 2001. You're like 'why not?' The quotative expressions of Glasgow adolescents. Journal of Sociolinguistics 5, 3-21.

McCawley, J. 1976. Lexical insertion in a transformational grammar without deep structure. In J. McCawley (ed.), Grammar and meaning: Papers on syntactic and semantic topics. New York: Academic Press. 155-66.

Meyer, P. 2000. The relevance of causality. In Couper-Kuhlen \& Kortmann (eds.). 9-34.

Morris, L. 1996. Time and cause in the English connector as. The LACUS Forum 23, $417-$ 28.

Mortelmans, T. 2006. Langacker's 'subjectification' and 'grounding': A more gradual view. In Athanasiadou et al. (eds.). 151-75.

Notess, G. 2002. Search engine statistics: Database total size estimates. Available at www.searchengineshowdown.com/statistics/sizeest.shtml.

Pander Maat, H. \& T. Sanders. 2000. Domains of use of subjectivity? The distribution of three Dutch causal connectives explained. In Couper-Kuhlen \& Kortmann (eds.). 57-82.

Pander Maat, H. \& T. Sanders. 2001. Subjectivity in causal connectives: An empirical study of language in use. Cognitive Linguistics 12, 247-73.

Pit, M. 2006. Determining subjectivity in text: The case of backward causal connectives in Dutch. Discourse Processes 41, 151-74.

Prince, E. 1980. Towards a taxonomy of given-new information. In P. Cole. (ed.), Radical pragmatics. New York: Academic Press. 223-56.

Rickford, J., T. Wasow, A. Zwicky \& I. Buchstaller. 2007. Intensive and quotative all: Something old, something new. American Speech 81, 3-31.

Scheibman, J. 2002. Point of view and grammar: Structural patterns of subjectivity in American English conversation. Amsterdam: Benjamins.

Stein, D. \& S. Wright (eds.) 1995. Subjectivity and subjectivisation. Cambridge: Cambridge University Press.

Sweetser, E. 1990. From etymology to pragmatics. Cambridge: Cambridge University Press.

Talmy, L. 1988. Force dynamics in language and cognition. Cognitive Science 12, 49-100.

Traugott, E. 1989. On the rise of epistemic meanings in English: An example of subjectification in semantic change. Language 65, 31-55.

Traugott, E. 1995. Subjectification in grammaticalisation. In Stein \& Wright (eds.). 31-54.

Traugott, E. in press. Revisiting subjectification and intersubjectification. In K. Davidse, H. Cuyckens \& L. Vandelanotte (eds.), Subjectification, intersubjectification, and grammaticalization. Berlin: Mouton de Gruyter. 
Traugott, E. \& R. Dasher. 2002. Regularity in semantic change. Cambridge: Cambridge University Press.

Traugott, E. \& B. Heine (eds.). 1991. Approaches to grammaticalization, vol. 1: Focus on theoretical and methodological issues. Amsterdam: Benjamins.

Traugott, E. \& E. König. 1991. Semantics-pragmatics of grammaticalization revisited. In Traugott \& Heine (eds.). 189-218.

Vandelanotte, L. 2004. From representational to scopal 'distancing indirect speech or thought': A cline of subjectification. Text 24, 547-85.

Verhagen, A. 2005. Constructions of intersubjectivity: Discourse, syntax, and cognition. Oxford: Oxford University Press.

Wilson, K. (ed.). 1993. The Columbia guide to standard American English. New York: Columbia University Press. Available at www.bartleby.com/68/.

Winter, J. 2002. Discourse quotatives in Australian English: Adolescents performing voices. Australian Journal of Linguistics 22, 5-21. 